\title{
Experimental and theoretical study of the energetic, morphological, and photoluminescence properties of $\mathrm{CaZrO}_{3}: \mathrm{Eu}^{3+}$
}

Marisa Carvalho Oliveira ${ }^{1,2}$, Renan A. Pontes Ribeiro ${ }^{3}$, Lourdes Gracia ${ }^{4}$, Sergio R. de Lazaro $^{3}$, Marcelo de Assis ${ }^{2}$, Mónica Oliva ${ }^{1}$, Ieda L. Viana Rosa ${ }^{2}$, Maria Fernanda do C. Gurgel $^{5}$, Elson Longo ${ }^{2}$, and Juan Andrés ${ }^{1, *}$

1 Department of Analytical and Physical Chemistry, Universitat Jaume I, Castelló E12071, Spain

2 CDMF-UFSCar, Universidade Federal de São Carlos, PO Box 676, 13565-905 São Carlos, SP, Brazil

3 Department of Chemistry, Universidade Estadual de Ponta Grossa, Av. General Carlos Cavalcanti, 4748, 84030-900, Ponta Grossa, PR, Brazil.

4 Department of Physical Chemistry, Universitat de Valencia, Burjassot E-46100, Spain

5 Department of Chemistry, Universidade Federal de Goiás, Regional Catalão, Av.Dr.Lamartine Pinto d eAvelar,75704-020, Catalão, GO, Brazil.

*E-mail: andres@qfa.uji.es

\begin{abstract}
In this study, we present a combined experimental and theoretical study of the geometry, electronic structure, morphology, and photoluminescence properties of $\mathrm{CaZrO}_{3}: \mathrm{Eu}^{3+}$ materials. The polymeric precursor method was employed to synthesize $\mathrm{CaZrO}_{3}: \mathrm{Eu}^{3+}$ crystals, while density functional theory calculations were performed to determine the geometrical and electronic properties of $\mathrm{CaZrO}_{3}: \mathrm{Eu}^{3+}$ in its ground and excited electronic states (singlet and triplet). These results were combined with X-ray diffraction (XRD) measurements to elucidate the local structural changes induced by the introduction of $\mathrm{Eu}^{3+}$ in the crystal lattice. This process results in the formation of intermediate levels in the band-gap ( $\left.E_{\text {gap }}\right)$ region, narrowing its width. The PL emissions were rationalized by characterizing the electronic structure of excited singlet and triplet electronic states, which provided deep insight into the main structural and electronic fingerprints associated of $\left[\mathrm{CaO}_{8}\right],\left[\mathrm{EuO}_{8}\right]$, and $\left[\mathrm{ZrO}_{6}\right]$ clusters. In addition, the Wulff construction, obtained from the first-principles calculations, was used to clarify the experimental morphologies. These results extend our fundamental understanding of the atomic processes that underpin the Eu doping of $\mathrm{CaZrO}_{3}$.
\end{abstract}




\section{Introduction}

Photoluminescent materials have attracted significant attention due to their technological applications in the electronic industry, such as energy-efficient lighting, lasers, medical imaging devices, spectroscopy, and others. In general, when photoluminescent materials are excited by photons or ionizing radiation, they can emit light in the visible, ultraviolet (UV), and infrared (IR) regions ${ }^{1-3}$. The fundamental mechanism associated with this process involves the trapping of excited electrons and holes in activators (which are impurity sites that generate intermediate states within the band-gap) and the recombination of electron-hole pairs, which results in the photoemission. In this sense, the structural and electronic properties exhibit a new equilibrium, showing as order-disorder effects change attractive and repulsive forces inside the solid through chemical bonds ${ }^{4}$. Perovskite materials with $\mathrm{ABO}_{3}$ formula are promising candidates in this field, due to their structural versatility and stability, and are widely used in the electronic industry because of their ability to display a wide range of physical and chemical properties, depending of the metal occupancies of the A and B sites ${ }^{5,6}$. The ideal perovskite structure has cubic symmetry ( $P m 3 m$ space group) ${ }^{7,8}$; however, the occurrence of local structural disorder in the A and B sites results in a large number of polymorphs with tetragonal, orthorhombic, rhombohedral, and other symmetries. Therefore, the intriguing properties associated with the perovskite materials have commonly been attributed to $\left[\mathrm{BO}_{6}\right]$ clusters distorted through cation displacements, octahedral rotations, doping, and tilting ${ }^{6,9}$.

Calcium zirconate $\left(\mathrm{CaZrO}_{3}, \mathrm{CZO}\right)$ is a representative member of the perovskite family, which has received considerable attention due to its exceptional dielectric, catalytic, and photoluminescence (PL) properties. This material has numerous scientific and technological applications, such as hydrogen sensors, luminescence hosts, capacitors, catalysts, and so on ${ }^{10-15}$. At room temperature, CZO crystallizes in the orthorhombic structure (Pnma space group), where $\mathrm{Ca}^{2+}$ cations occupy the center of eight-fold $\left[\mathrm{CaO}_{8}\right]$ clusters, while $\mathrm{Zr}^{4+}$ ions form a three-dimensional (3D) sublattice of corner-connected $\left[\mathrm{ZrO}_{6}\right]$ octahedra. In addition, all octahedral sites are slightly tilted with respect to their position in the ideal cubic perovskite structure, due to the mismatch of the alkaline earth ions to the A site clusters of the crystal structure ${ }^{13,16}$. 
In the past years, the introduction of impurity elements via doping has attracted considerable interest as a possible way to enhance the intensity of the PL emissions and to control the photogeneration process. In this context, rare-earth cations show an unusual mechanism involving the conversion of low-energy near-infrared photons to high-energy visible photons, known as up-conversion ${ }^{17}$. Therefore, several rare-earthdoped perovskites have been synthesized by various methods and showed superior PL emission, as well as other interesting properties. In particular, successful applications of $\mathrm{Eu}^{3+}, \mathrm{Tm}^{3+}, \mathrm{Dy}^{3+}, \mathrm{Yb}^{3+}$, and $\mathrm{Er}^{3+}$ cations to enhance the PL properties of CZO have been reported by several authors ${ }^{12,16-22}$. Shimizu et al. reported the synthesis of $\mathrm{Tb}-\mathrm{Mg}$ codoped CZO particles with enhanced luminescence intensity, attributed to the local lattice distortion resulting from the doping process ${ }^{18,23}$. Maurya et al. used solid-state reactions to synthesize $\mathrm{Ho}-\mathrm{Yb}$ codoped $\mathrm{CZO}$ nanoparticles with enhanced upconversion of green light, which showed promising potential for optical applications ${ }^{21}$.

Furthermore, several experimental studies reported the synthesis of Eu-doped CZO samples using different techniques. Sheetal et al. used a sol-gel combustion method to obtain CZO-Eu particles with remarkable red luminescence ${ }^{22}$. Katyayan and Agrawal used conventional solid-state reactions to obtain $\mathrm{Tb}$-Eu codoped $\mathrm{CZO}$ particles with high intensity and variable emissions, confirming the color tunability of the doped particles ${ }^{20}$. On the other hand, Singh et al. have been prepared Er-Yb codoped CZO compounds by the urea combustion route, obtaining strong energy transfer upconversion emission in the green and red spectral regions ${ }^{19}$. Despite the large number of experimental studies on Eu-doped $\mathrm{CZO}$ materials, the chemical and physical mechanisms associated with their superior PL emission remain unclear.

From a theoretical viewpoint, the investigation of PL emissions is a challenging task because it requires a detailed understanding of the excited states involved in the optical phenomena ${ }^{1,24}$. In our previous work, we presented a novel approach to explore ground (singlet) and excited (singlet and triplet) states involved in the experimental PL spectra of CZO nanoparticles ${ }^{25}$. This approach was successfully applied by our group to investigate the mechanism of PL emission in $\mathrm{SrTiO}_{3}, \mathrm{SrTiO}_{3}: \mathrm{Sm}, \mathrm{CaWO}_{4}, \mathrm{BaZrO}_{3}$, and $\mathrm{BaZr}_{1-\mathrm{x}} \mathrm{Hf}_{\mathrm{x}} \mathrm{O}_{3}$ solid solutions, based on the characterization of excited electronic states $^{26-31}$.

The present work combines theoretical and experimental analyses to investigate the PL mechanism and its relationship with the excited electronic states of Eu-doped CZO crystals. The main novelty of this study lies in the rationalization of the PL 
emission of these materials through the analysis of the structural and electronic orderdisorder effects associated with the Eu doping of the CZO matrix.

\section{Experimental procedures and computational details}

\subsection{Synthesis and characterization}

Pure $\mathrm{CZO}^{32}$ and europium-doped calcium zirconate $\left(\mathrm{CZO}: \mathrm{Eu}^{3+}\right)$ powders were prepared by the polymeric precursor method (PPM). The $\mathrm{CZO}: \mathrm{Eu}^{3+}$ powders were synthesized using calcium chloride dihydrate $\left(\mathrm{CaCl}_{2} \cdot 2 \mathrm{H}_{2} \mathrm{O}, 99 \%\right.$, Synth), zirconium oxychloride (IV) octahydrate $\left(\mathrm{ZrOCl}_{2} \cdot 8 \mathrm{H}_{2} \mathrm{O}, 99.5 \%\right.$, Sigma-Aldrich), europium oxide $\left(\mathrm{Eu}_{2} \mathrm{O}_{3}, 99 \%\right.$, Sigma-Aldrich), ethylene glycol $\left(\mathrm{C}_{2} \mathrm{H}_{6} \mathrm{O}_{2}, 99.9 \%\right.$, J. T. Baker), and citric acid monohydrate $\left(\mathrm{C}_{6} \mathrm{H}_{8} \mathrm{O}_{7} \cdot \mathrm{H}_{2} \mathrm{O}, 99.5 \%\right.$, J. T. Baker $)$.

Zirconium citrate was formed by dissolution of $\mathrm{ZrOCl}_{2} \cdot 8 \mathrm{H}_{2} \mathrm{O}$ in a citric acid aqueous solution under constant stirring. The citrate solution was stirred at $60{ }^{\circ} \mathrm{C}$ to obtain a clear homogeneous solution, and $\mathrm{CaCl}_{2} \cdot 2 \mathrm{H}_{2} \mathrm{O}$ was added to yield a $1: 1 \mathrm{Ca} / \mathrm{Zr}$ molar ratio and a 1:6 molar ratio of citric acid relative to the total molar amount of the metals used. Doping by $\mathrm{Eu}^{3+}$ ions was fixed to $10 \mathrm{~mol} \%$ by adding stoichiometric amounts of an $\mathrm{Eu}_{2} \mathrm{O}_{3}$ solution (prepared by dissolution of $\mathrm{Eu}_{2} \mathrm{O}_{3}$ in concentrated $\mathrm{HCl}$ ) to the solution of $\mathrm{Ca}^{2+}$ ions and $\mathrm{Zr}$ citrate. After homogenization of the solution, $\mathrm{C}_{2} \mathrm{H}_{6} \mathrm{O}_{2}$ was added to promote a polyesterification reaction, using an acid/ethylene glycol mass ratio fixed to 60:40. Pure CZO resin powders (prepared in advance) were initially heattreated at $400{ }^{\circ} \mathrm{C}$ for $4 \mathrm{~h}$ and then annealed at $900{ }^{\circ} \mathrm{C}$ for $2 \mathrm{~h}$. The corresponding crystalline profiles matched with JCPDS card No. 35-0790, showing that the pure and $10 \mathrm{~mol} \% \mathrm{Eu}^{3+}$-doped samples have an orthorhombic structure belonging to the Pcnm space group.

The pure and doped CZO powders were characterized by X-ray diffraction (XRD) with a Rigaku DMax 2500PC diffractometer using $\mathrm{Cu} \mathrm{K}_{\alpha}(\lambda=1.5406 \AA)$ radiation. Data were collected in a $2 \theta$ range from $10^{\circ}$ to $90^{\circ}$, with a $0.5^{\circ}$ divergence slit and a $0.3 \mathrm{~mm}$ receiving slit, in fixed-time mode, with a $0.02^{\circ}$ step size and a $1 \mathrm{~s} /$ point rate. PL spectra were collected with a Thermal Jarrel Ash Monospec 27 monochromator and a Hamamatsu R446 photomultiplier. The $350.7 \mathrm{~nm}$ wavelength from a krypton ion laser (Coherent Innova) was used as excitation source; the nominal output power of the laser was maintained at $200 \mathrm{~mW}$. Microstructural characterization was performed by 
field emission gun-scanning electron microscopy (FEG-SEM) using a Zeiss Supra $^{\text {TM }} 5$ instrument. UV-vis absorption spectra of the annealed samples were obtained in total diffuse reflectance mode with a Cary 5G spectrometer. All measurements were performed at room temperature.

\subsection{Computational details}

First-principles calculations within the periodic density functional theory (DFT) framework, using the hybrid B3LYP exchange-correlation functional, were performed with the CRYSTAL14 program ${ }^{33-35}$ to characterize the pure and $\mathrm{Eu}^{3+}$-doped CZO systems. All-electron basis sets were used to describe $\mathrm{Ca}^{36}, \mathrm{Zr}{ }^{37}$, and $\mathrm{O}^{38}$ atomic centers, whereas an effective core potential (ECP) pseudopotential, with 11 valence electrons described by $(5 \mathrm{~s} 5 \mathrm{p} 4 \mathrm{~d}) /[3 \mathrm{~s} 3 \mathrm{p} 3 \mathrm{~d}]$ (VTZ quality) basis sets, was used for the trivalent Eu atom ${ }^{39}$. According to the f-in-core approximation, the electrons of the $4 \mathrm{f}$ shell of $\mathrm{Eu}^{3+}$ are incorporated in the pseudopotential. Thus, an explicit treatment of the open $4 \mathrm{f}$ shell is not required, which represents an important advantage from a computational viewpoint.

Regarding the density matrix diagonalization, the reciprocal space net was described by a shrinking factor of 4 , corresponding to $36 k$-points generated according to the Monkhorst-Pack scheme ${ }^{40}$. The accuracy of the evaluation of the Coulomb and exchange series was controlled by five thresholds, whose adopted values were $10^{-8}, 10^{-8}$, $10^{-8}, 10^{-8}$, and $10^{-16}$. An orthorhombic supercell of 79 atoms, corresponding to $2 \times 1 \times 2$ conventional cells, was used to simulate the $\mathrm{CZO}: \mathrm{Eu}^{3+}(12.5 \%$ - doped) system, in which two $\mathrm{Ca}^{2+}$ ions were replaced by two $\mathrm{Eu}^{3+}$ ions and a calcium vacancy $\left(\mathrm{V}_{\mathrm{Ca}}\right)$ was created in order to neutralize the unit cell (Eq. 1).

$$
\mathrm{CaZrO}_{3}+\mathrm{Eu}(\mathrm{III}) \rightarrow \mathrm{Ca}_{0.8125} \mathrm{Eu}_{0.125} \mathrm{ZrO}_{3} \quad\left(+0.0625 \mathrm{~V}_{\mathrm{Ca}}\right)
$$

In addition, the surface energies ( $\left.E_{\text {surf }}\right)$ of the (001), (121), (100), (011), (201), (111), and (101) cleavage planes were calculated using the Wulff construction ${ }^{41}$. The Visualization for Electronic and Structural Analysis (VESTA) program ${ }^{42}$ was used to generate the Wulff construction and for visualizing the morphological mappings of $\mathrm{CZO}: \mathrm{Eu}^{3+}$ crystals. 
In order to understand the PL mechanism associated with the $\mathrm{CZO}: \mathrm{Eu}^{3+}(12.5 \%$ doped) material, excited states calculations were carried out considering for both excited singlet $\left(s^{*}\right)$ and triplet states $\left(t^{*}\right)$ derived from the singlet ground state $(s)$. In this case, the $t^{*}$ state was modeled by fixing the difference between spin-up $(\alpha)$ and spin-down $(\beta)$ populations $\left(n_{\alpha}-n_{\beta}=2\right)$ in the self-consistent field (SCF) calculations. The electronic structure was investigated by analyzing the band structures, the density of states (DOS), and the spin density isosurfaces.

It is important to point out that in this study the $\mathrm{Eu}^{3+}$ doping of the $\mathrm{CZO}$ matrix was modeled allowing lattice and atomic position relaxation for the singlet state, and calculations were carried out for both bulk and slab models, using the optimized cell for ordered and disordered models of CZO reported in our previous work ${ }^{25}$; this enabled the computational treatment of the main electronic features associated with the doping process and the optical properties.

\section{Results and discussion}

\subsection{X-ray diffraction analysis}

Figs. 1a and $1 \mathbf{b}$ show the XRD patterns of pure and $10 \mathrm{~mol} \% \mathrm{Eu}^{3+}$-doped $\mathrm{CZO}$ crystals, respectively. The as-synthesized samples display a pure orthorhombic single phase ( $a=5.591 \AA, b=8.017 \AA, c=5.761 \AA$ ) with Pcnm space group, according to the Inorganic Crystal Structure Database (ICSD) card number $97464^{43}$. Both samples show well-defined peaks, denoting a high degree of crystallinity, without any secondary phases.

\section{FIGURE 1}

In both crystals, the strongest peak around $2 \theta=31.60^{\circ}$ corresponds to the (121) crystalline plane; however, doping with $\mathrm{Eu}^{3+}$ cations alters the lattice parameters, due to the different electronic density with respect to $\mathrm{Ca}^{2+}$ ions and to the introduction of structural defects, with the formation of clusters of $\left[\mathrm{EuO}_{8}\right]$ and $\mathrm{V}_{\mathrm{Ca}}$ sites, which can be seen from the amplification of the strongest diffraction peak (Fig. 1b) ${ }^{44}$. This observation is a strong indication of the successful substitution of $\mathrm{Ca}^{2+}$ by $\mathrm{Eu}^{3+}$ in the $\mathrm{A}$ sites $\left(\mathrm{AZrO}_{3}\right)$ of the $\mathrm{CZO}$ material ${ }^{45}$. This maintained the charge balance in the syntheses, generating calcium vacancies. In this way, the crystal is populated with 
calcium vacancies, which result in p-type semiconductor properties and in a relaxation of the crystalline lattice.

The PPM has been employed for the synthesis of various systems, such as $\mathrm{LnMn}_{0.5} \mathrm{Fe}_{0.5} \mathrm{O}_{3}(\mathrm{Ln}=\mathrm{La}, \mathrm{Pr}, \mathrm{Nd}, \mathrm{Sm}$, and $\mathrm{Gd}){ }^{46}, \mathrm{Ca}_{\mathrm{x}} \mathrm{Bi}_{(1-\mathrm{x})} \mathrm{FeO}_{3}(\mathrm{x}=0.0,0.1,0.2$, $0.3)^{47}, \mathrm{Ca}_{0.98} \mathrm{Er}_{0.01} \mathrm{Yb}_{0.01} \mathrm{TiO}_{3}{ }^{48}, \mathrm{SrZrO}_{3}$ and $\mathrm{SrTiO}_{3}{ }^{49}$, as well as $\mathrm{SrSn}_{1-\mathrm{x}} \mathrm{Ti}_{\mathrm{x}} \mathrm{O}_{3}{ }^{50}$.

\subsection{Optical properties}

It is well known that the optical properties of molecular systems are intrinsically associated with excited electronic states, such as $s^{*}$ and $t^{*}$ states. However, the solidstate theory relies on electron-hole pair generation to explain electrical and optical phenomena. Here, we present optical experiments on $\mathrm{CZO}$ and $\mathrm{CZO}: \mathrm{Eu}^{3+}$ materials to provide a new and deeper interpretation of optical effects in the solid state.

In previous studies, we have shown that the defect-induced band-gap $\left(E_{\text {gap }}\right)$ reduction in crystalline structures is associated with intermediate electronic levels introduced in the band-gap ${ }^{51-56}$. Such mechanism has been improved a lot with description from $s^{*}$ and $t^{*}$ states. We consider such electronic states as the quantum evidence of the electron-hole pair generation of solid-state theory. Then, the interpretation of Figs. 2a and $\mathbf{2 b}$ is consistent with our previous reports.

The introduction of $\mathrm{Eu}^{3+}$ dopants causes significant changes in the $E_{\text {gap }}$ of $\mathrm{CZO}$, originating from the intermediate electronic levels; these effects can be investigated in higher detail based on the properties of the $s^{*}$ and $t^{*}$ states. The results of the experiments (Fig. 2) show that the $E_{\text {gap }}$ decreases from 5.60 to $3.82 \mathrm{eV}$ going from CZO to $\mathrm{CZO}: \mathrm{Eu}^{3+}$. The marked $E_{\mathrm{gap}}$ reduction $(1.78 \mathrm{eV})$ is associated with the high density of defects introduced by the substitution of $\mathrm{Ca}^{2+}$ by $\mathrm{Eu}^{3+}$ cations ${ }^{57}$.

\section{FIGURE 2}

The PL spectra can be used to investigate how the optical properties are affected by the $\mathrm{Eu}^{3+}$ doping process. The direct inspection of a luminescence profile is an effective and rapid way to detect changes in the electronic excitations and corresponding alterations in the electronic energy levels. Therefore, it is important to connect the PL spectra with the energy level diagram, in order to identify the nature of the photoemission. 
In Figure 3, the PL spectra of pure $\mathrm{CZO}$ and doped $\mathrm{CZO}: \mathrm{Eu}^{3+}$ materials are displayed. For the later, the spectrum is almost entirely flat, as it should be expected for an excitation far below the pure crystal absorption threshold; however, at the doped $\mathrm{CZO}: \mathrm{Eu}^{3+}$, there is the presence of defects in this material that can be associated with $\mathrm{Ca}$ vacancies generated by the structural and electronic changes of the $\left[\mathrm{EuO}_{8}\right]$ clusters in the crystalline network. The electronic states involved in the luminescence process were obtained from the energy level diagram indicating the transition probabilities for $\mathrm{Eu}^{3+}$ ions.

\section{FIGURE 3}

The electronic transitions associated to the ${ }^{5} \mathrm{D}_{0} \rightarrow{ }^{7} \mathrm{~F}_{j}(j=0,1,2,3,4,5)$ emissions occur between 570 and $720 \mathrm{~nm}$ (see Fig. S1). In particular, the ${ }^{5} \mathrm{D}_{0} \rightarrow{ }^{7} \mathrm{~F}_{2}$ transition is allowed; however, the electric dipole mechanism is significantly influenced by the crystalline field (hypersensitive transition), while the magnetic dipole mechanism is less affected by it. Therefore, this transition can be considered as a reference for all transitions occurring in the system ${ }^{58-60}$. The area ratio of the peaks corresponding to the ${ }^{5} \mathrm{D}_{0} \rightarrow{ }^{7} \mathrm{~F}_{2}$ and ${ }^{5} \mathrm{D}_{0} \rightarrow{ }^{7} \mathrm{~F}_{1}$ transitions provides valuable information on the changes in the environment around the $\mathrm{Eu}^{3+}$ ions and is a useful tool to measure the degree of distortion in the A sites, which introduces asymmetry in the electronic distribution and facilitates the charge transfer process ${ }^{61},{ }^{57},{ }^{45}$. For the $\mathrm{CZO}: \mathrm{Eu}^{3+}$ sample, we obtained a ${ }^{5} \mathrm{D}_{0} \rightarrow{ }^{7} \mathrm{~F}_{2} / \mathrm{D}_{0} \rightarrow{ }^{7} \mathrm{~F}_{1}$ peak intensity ratio of 5.14 . For similar systems, such as $\mathrm{CaTiO}_{3}$ doped with $\mathrm{Eu}^{3+}$, the ratios between the intensities of $\mathrm{D} \rightarrow \mathrm{F}$ electronic transitions were between 2 and 4, with lower values associated with a higher symmetry of the $\mathrm{Eu}^{3+}$ site 45. When applied to the present $\mathrm{CZO}: \mathrm{Eu}^{3+}$ samples, the same analysis yielded a ${ }^{5} \mathrm{D}_{0} \rightarrow{ }^{7} \mathrm{~F}_{2} /{ }^{5} \mathrm{D}_{0} \rightarrow{ }^{7} \mathrm{~F}_{1}$ ratio of 5.14 , showing that the $\mathrm{Ca}^{2+}$ and $\mathrm{Eu}^{3+}$ ions in $\mathrm{CZO}: \mathrm{Eu}^{3+}$ were located in low-symmetry or more disordered sites.

\subsection{Theoretical analysis}

In this section, we present theoretical results supporting a new interpretation of optical properties in the solid state. To this purpose, we present a new quantum model linking the generation of electron-hole pairs to the excited electronic states. 
The orthorhombic structure of CZO is displayed in Figs. 4(a-c) in terms of its component clusters; the figure illustrates the substitution of $\mathrm{Eu}^{3+}$ in the $\left[\mathrm{CaO}_{8}\right]$ cuboctahedral sites, while the $\left[\mathrm{ZrO}_{6}\right]$ sites remain unchanged as octahedral sites. The replacement of $\mathrm{Eu}^{3+}$ generates $\mathrm{V}_{\mathrm{Ca}}$ sites in the host matrix, required to neutralize the unit cell (Eq. 1). According to theoretical calculations, the lattice relaxation percentage with the Eu inclusion is less than 3\%. In addition, the farther clusters of the substitution and of the $\mathrm{Ca}$ vacancy have less distorted $\mathrm{Ca}-\mathrm{O}$ bonds, while the $\left[\mathrm{EuO}_{8}\right]$ clusters and the nearest $\mathrm{Ca}-\mathrm{O}$ coordination clusters and close to the vacancy present a greater distortion. In terms of the cation replacement and vacancy formation mechanisms associated to the doping process, the crystalline structure of $\mathrm{CZO}: \mathrm{Eu}^{3+}$ is expected to exhibit a new equilibrium between the attractive and repulsive interactions established through chemical bonds in the solid, resulting in a singular electronic structure compared to pure $\mathrm{CZO}$, which can in turn produce interesting electronic properties.

\section{FIGURE 4}

\subsubsection{Electronic structure}

Precise control of several photoassisted properties (photoluminescence, photocatalysis, photodegradation, and others) is often related to electronic structure engineering, in which different kinds of mechanisms such as doping, vacancy formation, structural distortions, etc. allow redistributing the electronic density (mainly) around the band-gap region. Charge- and spin-resolved analyses are important tools to rationalize the electronic structure of solid-state materials. Therefore, we calculated the DOS and band structure profiles (Figs. 5a and 5b). Considering the importance of taking into account the presence of excited states in order to accurately describe the effect of electron-hole pair generation and recombination processes on the photoinduced properties, in this study we investigated excited singlet $\left(s^{*}\right)$ and triplet $\left(t^{*}\right)$ states by combining the analyses mentioned above. The main purpose was to rationalize the PL emission of $\mathrm{CZO}: \mathrm{Eu}^{3+}$ following an approach similar to that employed in our previous study of pure $\mathrm{CZO}^{25}$.

\section{FIGURE 5}


The experimental values of $E_{\text {gap }}$ shown in Fig. 2 are $5.60 \mathrm{eV}$ (pure CZO) and $3.82 \mathrm{eV}\left(\mathrm{CZO}: \mathrm{Eu}^{3+}\right)$. Our previous DFT calculations for pure $\mathrm{CZO}{ }^{25}$ yielded an $E_{\text {gap }}$ value of $6.23 \mathrm{eV}$, in agreement with the experimental results. In addition, the $s, s^{*}$ (Fig. S2), and $t^{*}$ (Fig. 5) calculations for $\mathrm{CZO}: \mathrm{Eu}^{3+}$ (12.5\%-doped) gave $E_{\text {gap }}$ values of 5.09, 4.90, and $3.88 \mathrm{eV}$, respectively; therefore, the main electronic state associated with the UV-vis results (Fig. 2) is the $t^{*}$ one. The projected DOS for the $t^{*}$ model (Fig. 5) show that the upper levels of the valence band (VB) consist mainly of $\mathrm{O}$ orbitals, while the conduction band $(\mathrm{CB})$ is predominantly formed by $\mathrm{Zr}$ and Eu orbitals, with a small contribution from Ca orbitals, and the same results are found for the $s$ and $s^{*}$ states (Fig. S2). In addition, it was observed that the degenerate states of both the valence band maximum (VBM) and conduction band minimum (CBM) are sensitive to the $s^{*}$ and $t^{*}$ electronic states, creating an excitation mechanism capable of describing the generation of electron-hole pairs based on quantum chemistry. In fact, the comparison of the DOS profiles for the $s$ and $s^{*}$ states (Fig. S2) shows that the bands located between the VBM and CBM in the $s$ state were displaced to a higher energy in $s^{*}$. Furthermore, the transition for the $t^{*}$ perturbs both levels evidencing a band separation in both VB and CB. This can be attributed to the existence of non-degenerate energy levels for the excited $s^{*}$ and $t^{*}$ states, which are controlled by the spin multiplicity.

The analysis of the spin density is a useful tool to understand the nature and localization of the electron-hole pair originated from electronic excitation. It is important to point out that the spin density distributions (in $e / b \mathrm{bhr}^{3}$ units) were calculated using a regular 3D grid of points, enabling the analysis of the spin-resolved density matrix based on the difference between the alpha- and beta-spin occupations. In this way, spin density difference maps provide a pictorial representation of the unpaired electron density distribution. The calculated spin density distribution for the $t^{*}$ state of $\mathrm{CZO}: \mathrm{Eu}^{3+}$ is shown in Fig. 6. The distribution indicates that the spin density is predominantly localized on the $\mathrm{Zr}$ and $\mathrm{O}$ atoms, with a minor contribution on the $\mathrm{Eu}$ atoms. Furthermore, the largest spin populations were found closer to $\left[\mathrm{EuO}_{8}\right]$ clusters, suggesting that the doping process induces local disorder on the electronic density distribution, due to the oxygen-mediated interaction between $\mathrm{Eu}$ - and $\mathrm{Zr}$-centered clusters $\left(\left[\mathrm{EuO}_{8}\right]\right.$ and $\left[\mathrm{ZrO}_{6}\right]$, respectively).

\section{FIGURE 6}


As discussed above, the $\mathrm{Eu}^{3+}$ doping process of pure $\mathrm{CZO}$ is supported by the presence of calcium vacancies, which balance the excess charge and neutralize the unit cell (Eq. 1). In particular, $\left[\mathrm{ZrO}_{6}\right]$ clusters located near to a $\mathrm{V}_{\mathrm{Ca}}$ site play a key role in the stabilization of the $t^{*}$ state. A possible explanation for this result is the charge/spin density reorganization on the neighboring clusters, which increases the electron density population along the oxygen-mediated $\left[\mathrm{EuO}_{8}\right]-\left[\mathrm{ZrO}_{6}\right]$ interaction. In contrast, both $\left[\mathrm{AO}_{8}\right](\mathrm{A}=\mathrm{Ca}, \mathrm{Eu})$ and $\left[\mathrm{ZrO}_{6}\right]$ clusters contribute to the spin population in $\mathrm{CZO}: \mathrm{Eu}^{3+}$.

In the following, we discuss the spin distributions calculated for five $\mathrm{CZO}: \mathrm{Eu}^{3+}$ surface models in terms of their undercoordinated clusters and impurity centers $\left(\mathrm{Eu}^{3+}\right.$ and $\mathrm{V}_{\mathrm{Ca}}$ ). In general, similar spin density distributions were observed for all investigated surfaces, in agreement with the results obtained for the bulk. The results presented in Fig. 6 indicate that the exposed surfaces are formed by $[\mathrm{ZrO}]_{\mathrm{n}}(\mathrm{n}=3-5)$ clusters exhibiting the largest spin density population, while $[\mathrm{EuO}]_{\mathrm{n}}(\mathrm{n}=4-6)$ clusters only give a minor contribution to the $t^{*}$ state stabilization. Therefore, similar to the bulk, the perturbation of the electronic density is associated to the oxygen-mediated [EuO 8 $\left[\mathrm{ZrO}_{6}\right]$ interaction and, consequently, to the generation of electron-hole pairs on the surface.

As expected for surface models, dangling bonds have a strong effect on the electronic structure of the $\mathrm{CZO}: \mathrm{Eu}^{3+}$ material. The standard procedure to generate surface models as slabs cut from the bulk structure leads to the generation of oxygen vacancies, resulting in undercoordinated clusters. In this way, the symmetry breaking process in the component clusters alters the local environment on the surface, creating intermediate energy levels in the $E_{\text {gap }}$ region. These new intermediate levels have high energy because they originate from the uncoupling of degenerate orbitals, and act as traps of excited electrons. In fact, the unpaired spin density displayed in Fig. 6 is predominantly localized on undercoordinated clusters exposed of the surface, indicating that the electron-hole pair generation is assisted by migration of electrons from bulk to surface. From this point of view, our results suggest that the CZO:Eu ${ }^{3+}$ surface can act as a photocatalytic semiconductor, in which the excited states can produce radical species from the adsorption of $\mathrm{O}_{2}$ and $\mathrm{H}_{2} \mathrm{O}$ molecules on the undercoordinated clusters. Doping with $\mathrm{Eu}^{3+}$ cations then generates a new spin density distribution; being located on the oxygen-mediated $\left[\mathrm{EuO}_{8}\right]-\left[\mathrm{ZrO}_{6}\right]$ interaction, this spin density can now be trapped in empty $\mathrm{Zr}(4 \mathrm{~d})$ and $\mathrm{Eu}(4 \mathrm{f})$ orbitals. 
In order to clarify the effect of $\mathrm{Eu}^{3+}$ cations on the PL emissions of $\mathrm{CZO}$, we propose a general scheme combining the DOS, band structure, and spin density calculations for $s, s^{*}$, and $t^{*}$ states, as shown in Fig. 7. Initially, the $\mathrm{Eu}^{3+}$ doping process induces the formation of $\mathrm{V}_{\mathrm{Ca}}$ sites that perturb the $\mathrm{VB}$ energy levels, and promotes the insertion of $4 \mathrm{f}$ orbitals in the CBM; in other words, intermediate energy levels are introduced in the $E_{\text {gap }}$ region, reducing the energy required for electron transfer (Fig. 7a). The next step is the photoinduced electron transfer from the VB to the CB, generating an electron-hole pair within the $\mathrm{CZO}: \mathrm{Eu}^{3+}$ electronic structure (Fig. 7b). This step is crucial because it offers a new interpretation of the optical properties of a material. We link the excited states theory to the generation of electron-hole pairs, providing a deeper understanding of optical effects in the solid state. This new approach was proposed in previous studies and has been confirmed in the present work ${ }^{25}$. The proposed connection between excited states and optical properties is well established in quantum chemical approaches; however, the present quantum evidence of dangling bonds generating electron-trapping levels and localizing spin density is entirely new. Therefore, this quantum modeling analysis represents a highly significant contribution. In particular, the contribution of both empty $\mathrm{Zr}(4 \mathrm{~d})$ and $\mathrm{Eu}(4 \mathrm{f})$ states to the CBM enables charge competition between these metallic centers. The photoluminescent effect ultimately originates from electron decay processes, which take place more efficiently in $\mathrm{CZO}: \mathrm{Eu}^{3+}$ than $\mathrm{CZO}$.

\section{FIGURE 7}

\subsection{Morphology analysis}

The FEG-SEM technique is a key tool to analyze the powder surface morphology of the samples synthesized in this work, because XRD is not suitable for characterizing minor structural modifications and identifying the relevant correlations between the PL response and structural changes in the sample. Fig. 8 shows FE-SEM images of the $\mathrm{CZO}$ and $\mathrm{CZO}: \mathrm{Eu}^{3+}$ powders, revealing the presence of agglomerates with complex morphology and a large number of exposed crystalline faces. This softagglomerated powder morphology is a common product of the polymeric precursor synthesis; with increasing temperature, the release of gas from the ongoing carbothermal reaction results in the formation of pores of different sizes; then, the 
morphology becomes gradually more ordered with a decrease in the density of defects, and changes from amorphous, to semicrystalline, to crystalline with a low defect density, enabling the construction of theoretical morphology maps. This fact is proven by the low luminescent broadband of pure CZO. On the other hand, the doped CZO sample shows well-defined PL peaks of $\mathrm{Eu}^{3+}$ ions, reflecting the crystallinity of the material, i.e., the effect of the crystalline field.

\section{FIGURE 8}

To clarify the influence of the defects introduced by the $\mathrm{Eu}^{3+}$ dopants on different crystalline facets, we obtained theoretical models of CZO crystals using the Wulff construction $^{62}$, according to the procedure applied in our previous studies ${ }^{25,63-66}$. In particular, we obtained Wulff constructions corresponding to the ideal structure of $\mathrm{CZO}: \mathrm{Eu}^{3+}$ in $s^{*}$ and $t^{*}$ states. In addition, Fig. 9 illustrates the approach used to predict the morphology changes of the crystals and evaluate their equilibrium shape based on surface thermodynamics and excited state properties.

\section{FIGURE 9}

The analysis in Figs. 9a and 9b shows that the ideal morphology for $\mathrm{CZO}: \mathrm{Eu}^{3+}$ in the $s^{*}$ and $t^{*}$ states is controlled by the (111), (001), (011), and (100) surfaces. However, the two states show different ideal morphologies: for the $s^{*}$ state, the (111), (001), (100), and (011) surfaces contribute 61.03\%, 29.04\%, 8.07\%, and $1.86 \%$, respectively, of the total surface area, whereas for the $t^{*}$ state the (111), (100), (001), and $(011)$ contributions are $45.63 \%, 23.08 \%, 19.76 \%$, and $11.53 \%$, respectively. The different morphology of the $s^{*}$ and $t^{*}$ states can be attributed to a different order of stability of the surfaces. The $E_{\text {surf }}$ values indicate the order of stability $(111)>(001)>$ $(011)>(100)>(121)$ for the $s^{*}$ state, whereas the $(111)>(100)>(011)>(001)>(121)$ stability order was observed for $t^{*}$ state. Moreover, the (121) facet was found to be the most unstable surface for the $\mathrm{CZO}: \mathrm{Eu}^{3+}$ material, revealing an opposite stability order compared to pure CZO, for which $(121)$ is the plane with the lowest $E_{\text {surf }}{ }^{25}$. This observation complements the differences between the (121) peaks observed in the XRD patterns of the two samples (Fig. 1), suggesting that the Eu doping induces disorder in the crystalline structure of CZO, mainly in the (121) plane. 


\section{Conclusions}

$\mathrm{CZO}: \mathrm{Eu}^{3+}$ was successfully synthesized using the polymeric precursor method. The XRD analysis revealed the good crystallinity and single-phase characteristics of the sample. A combination of experimental techniques and first-principles calculations showed that the introduction of $\mathrm{Eu}^{3+}$ cations and the creation of calcium vacancies in the CZO structure resulted in a reduction of the band-gap. In addition, theoretical calculations based on the excited electronic states were employed to interpret the photoluminescent emissions of the $\mathrm{CZO}: \mathrm{Eu}^{3+}$ samples. FEG-SEM images revealed that the pure and Eu-doped $\mathrm{CZO}_{3}$ materials exhibited similar morphology, indicating minor changes in the shape of CZO particles upon doping. From a theoretical point of view, the analysis of the faceted morphologies calculated from the Wulff construction using the (111), (100), (011), (001), (201), (101), and (121) cleavage planes of the CZO:Eu ${ }^{3+}$ crystal allowed determining the surface energies corresponding to the complex morphologies observed experimentally.

\section{Acknowledgements}

The authors acknowledge the financial support of the agencies: Generalitat Valenciana for Prometeo/2016/079 and ACOMP/2014/270, ACOMP/2015/1202, Ministerio de Economia y Competitividad, project CTQ2015-65207-P, Programa de Cooperacion Cientifíca con Iberoamerica (Brasil) of Ministerio de Educacion (PHBP14-00020) and, Fundação de Amparo à Pesquisa do Estado de São Paulo (FAPESP) (2013/07296-2). J.Andres acknowledges the Ministerio de Economia y Competitividad, "Salvador Madariaga" program, PRX15/00261. M.C.Oliveira acknowledges Generalitat Valencia for the Santiago Grisolia program 2015/033. R. Ribeiro and S. R. de Lazaro thanks the UEPG, CAPES and Fundação Araucaria for the financial support. 
(a)

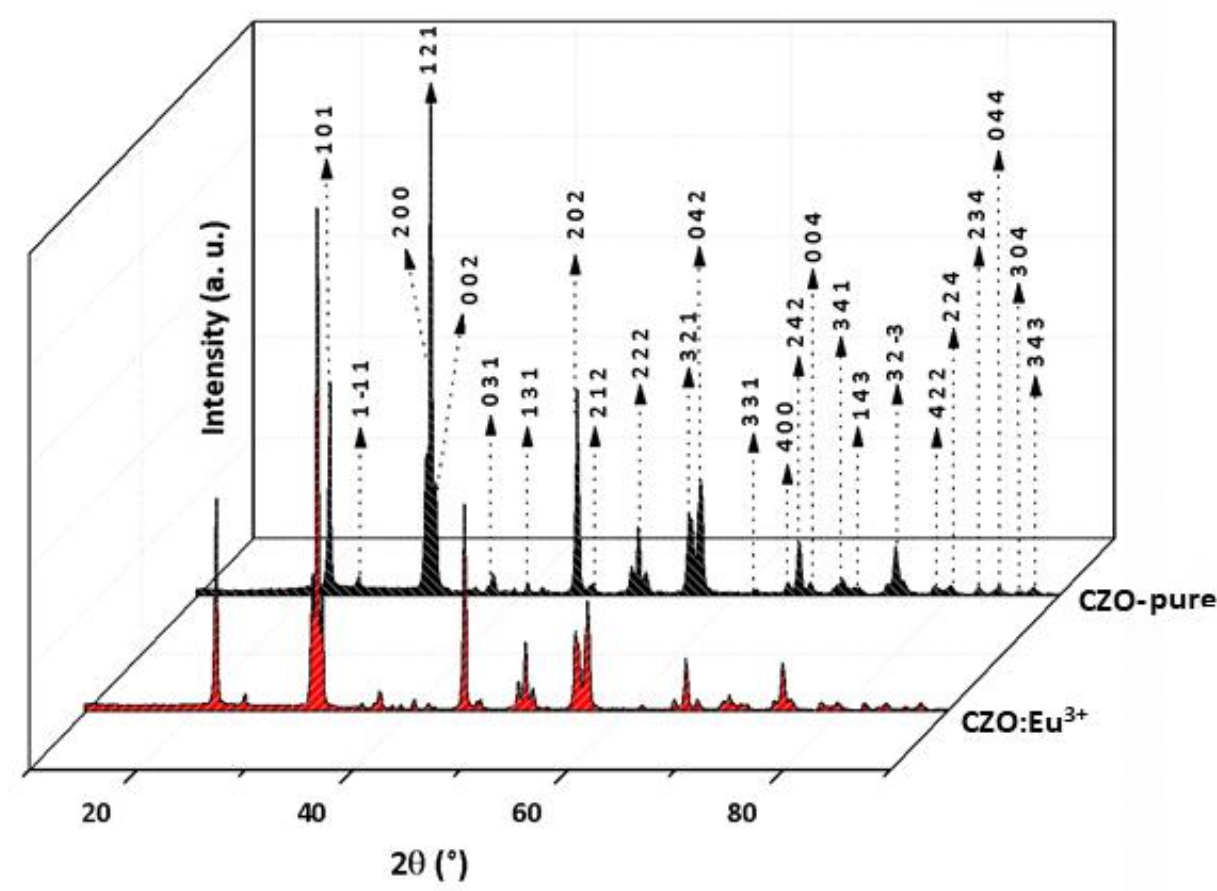

(b)

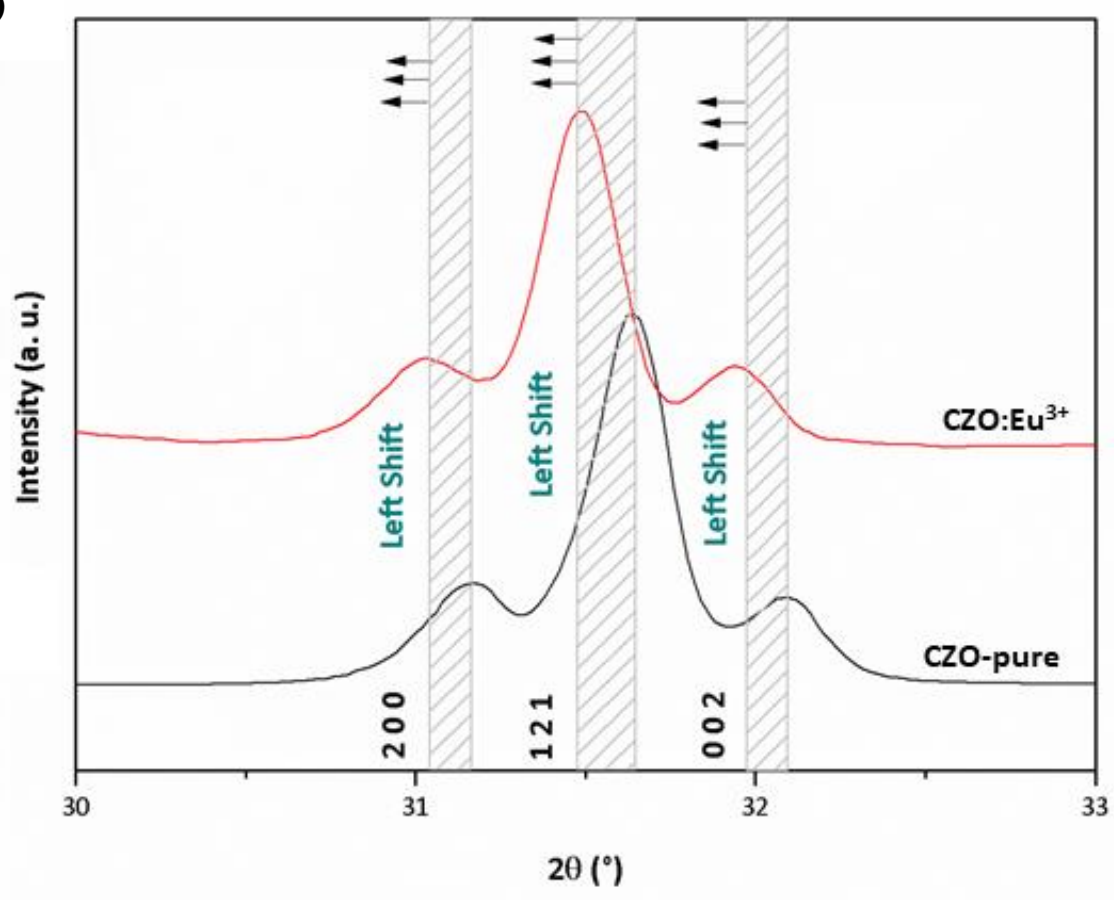

Fig. 1. XRD patterns for (a) pure CZO sample with plans indexed and $\mathrm{Eu}^{3+}$ doped (10\%) samples. (b) Displacement for left shift of the (200), (121) and (002) peaks. 
(a)

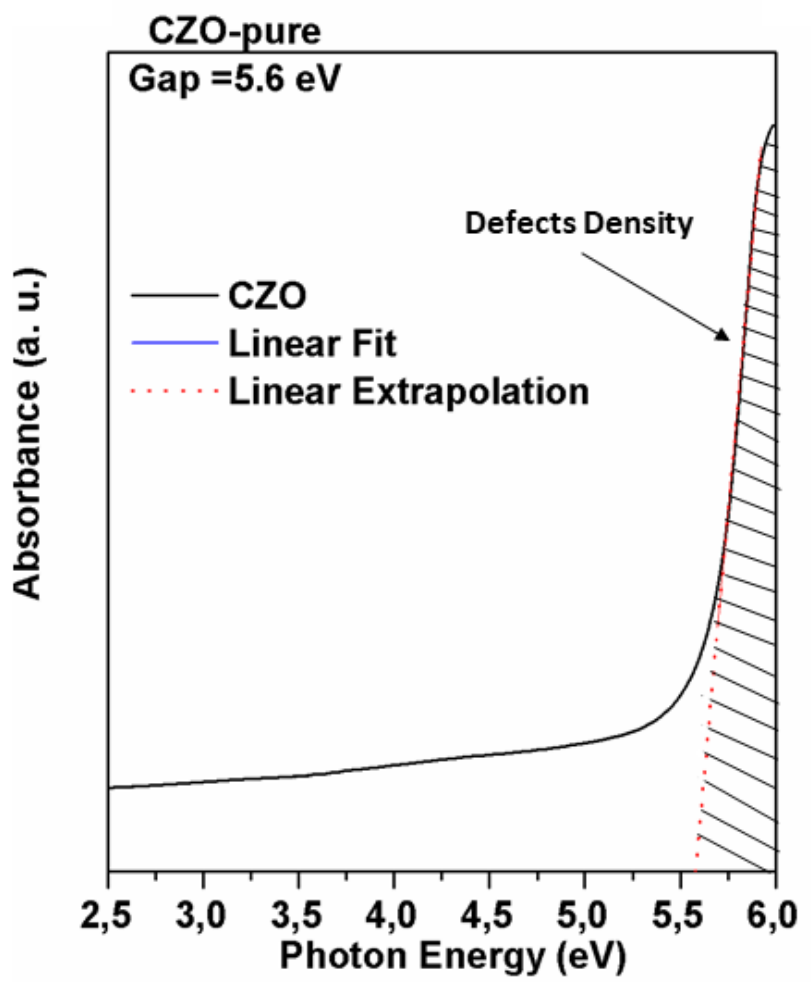

(b)

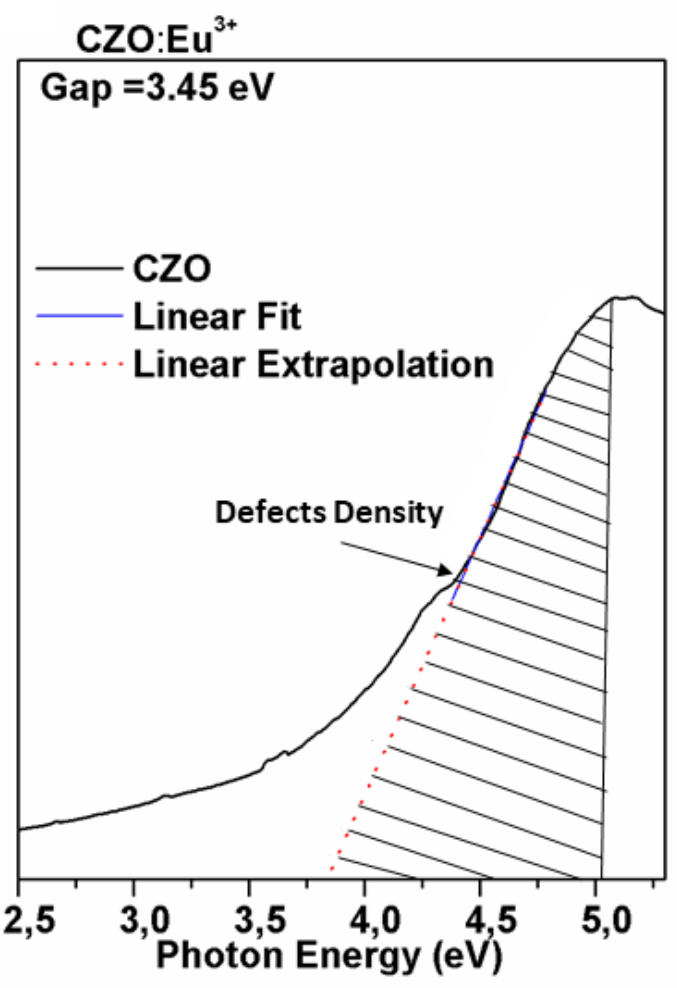

Fig. 2. UV-vis absorption spectrum. (a) CZO and (b) CZO:Eu ${ }^{3+}$ doped (10\%). 


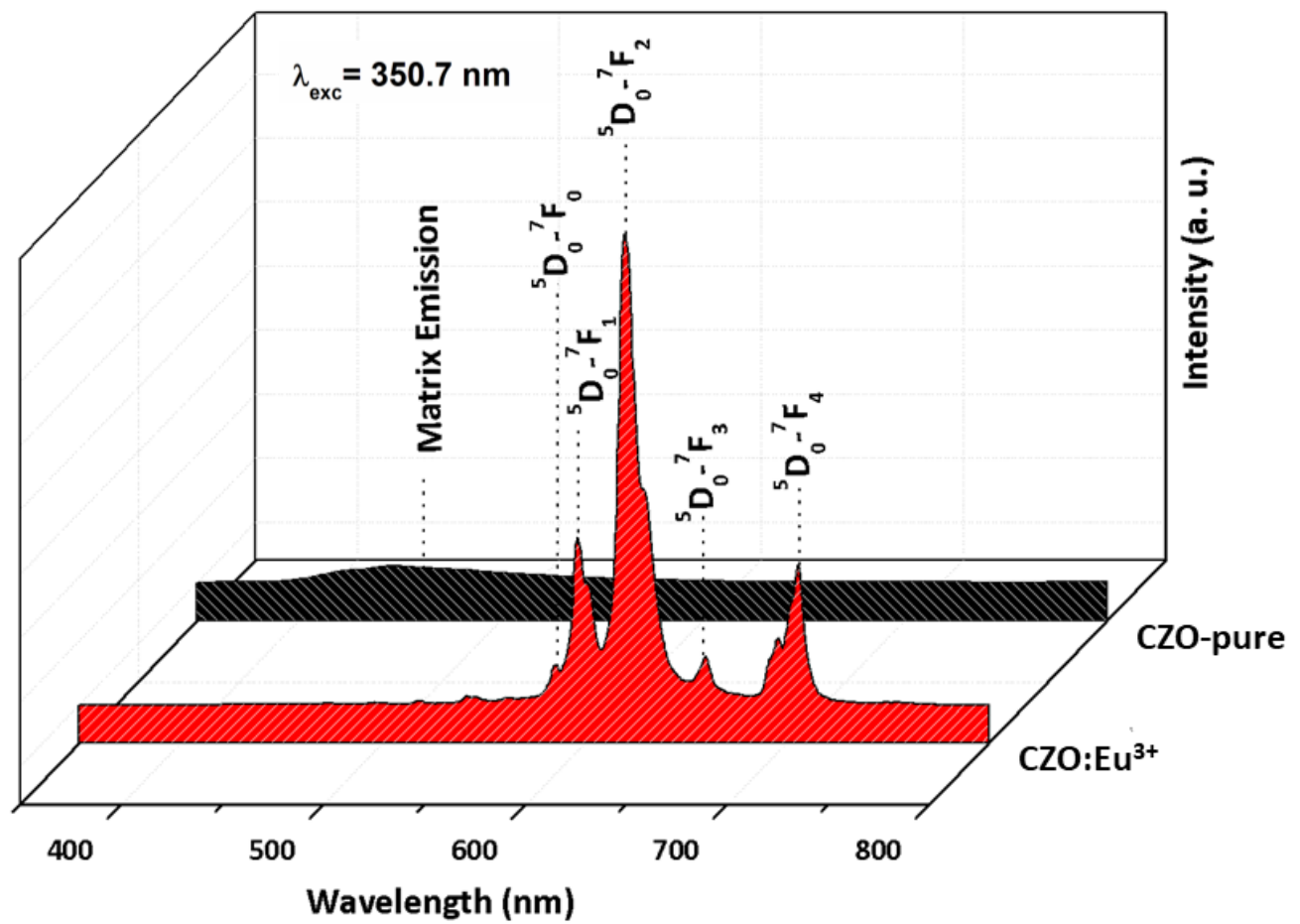

Fig. 3. Photoluminescence spectra excited at $350.7 \mathrm{~nm}$ of $\mathrm{Eu}^{3+}$ emission. 
a)

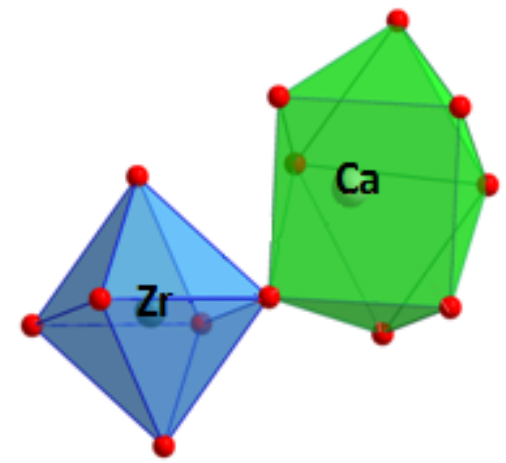

b)

c)
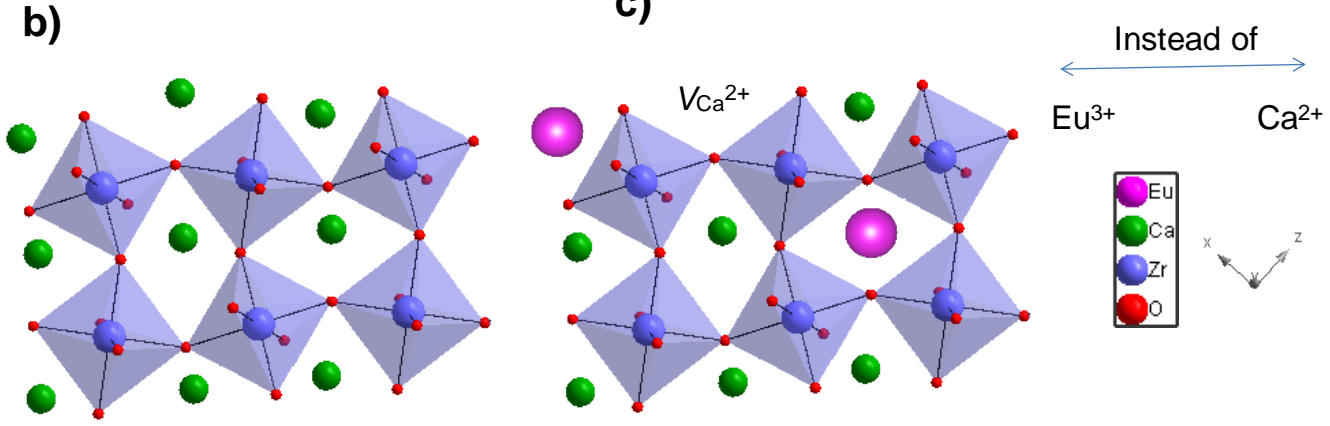

Fig. 4. $\mathrm{CZO}$ crystalline structure represented by polyhedral clusters. (a) $\left[\mathrm{ZrO}_{6}\right]$ and $\left[\mathrm{CaO}_{8}\right]$ clusters in blue and green colors, respectively. (b) Orthorhombic unit cell of the pure $\mathrm{CZO}$ and (c) $\mathrm{Eu}^{3+}$ doped. 
a)

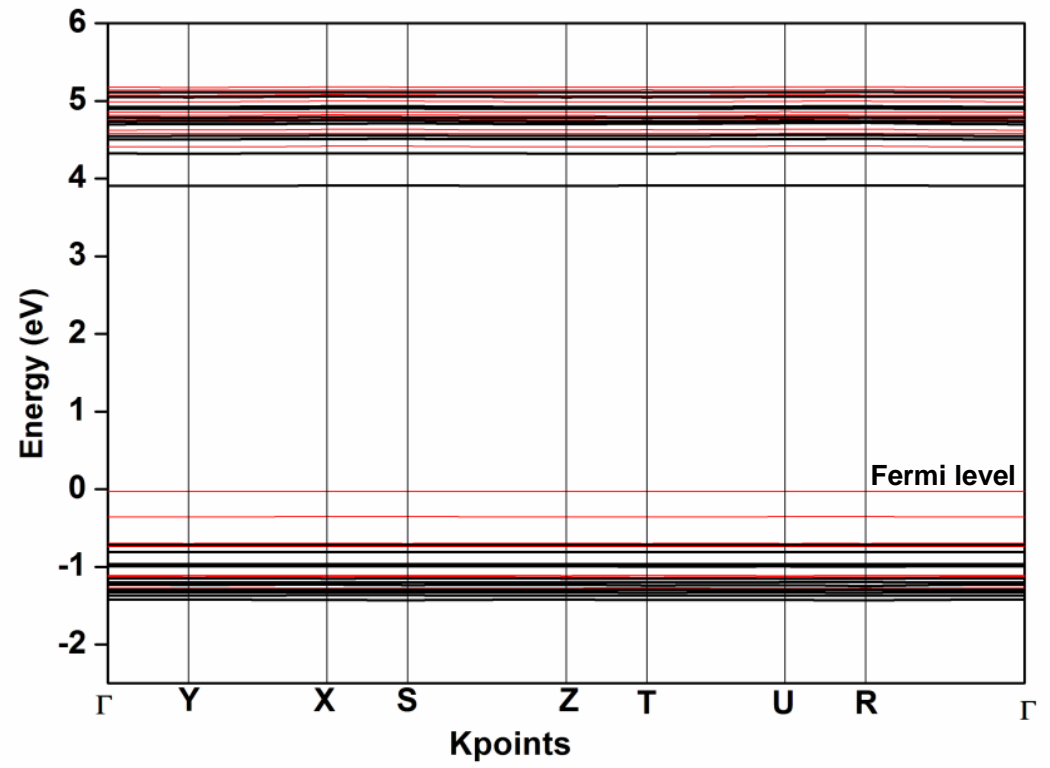

b)

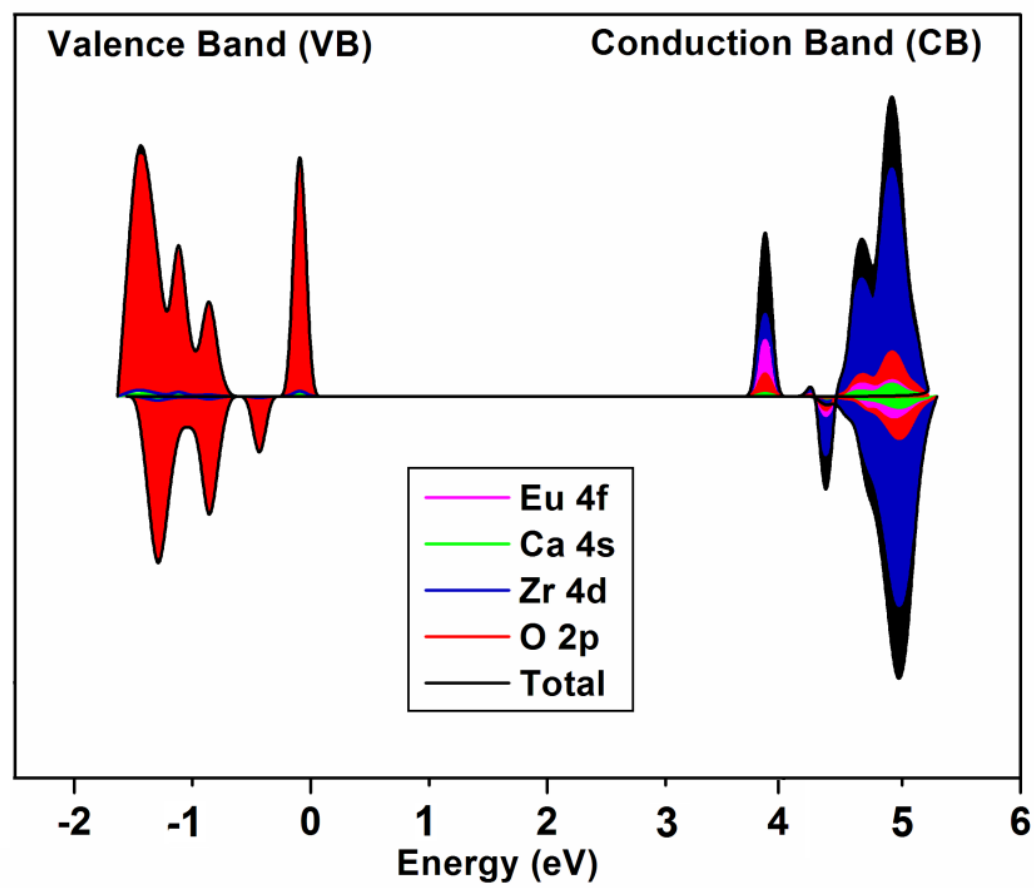

Fig.5. Electronic structure for CZO:Eu (12.5\%) in triplet state. (a) Band structures and (b) projected DOS on atomic levels of CZO:Eu ${ }^{3+}(12.5 \%)$ model. 


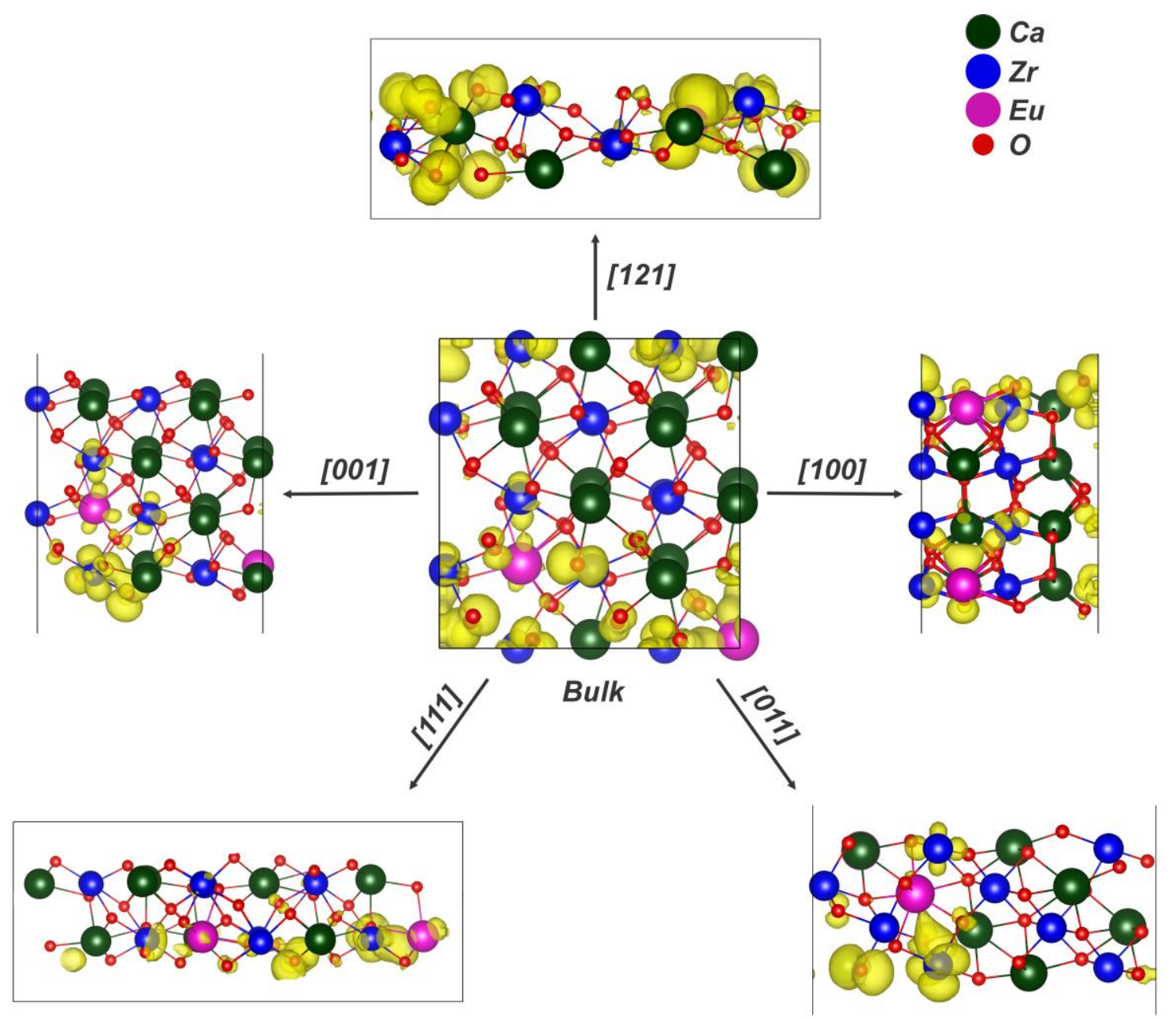

Fig. 6. A schematic representation for spin density isosurfaces (in yellow) calculated for bulk and surface models of $\mathrm{CZO}: \mathrm{Eu}^{3+}(10 \%)$ in triplet state $\left(t^{*}\right)$. 


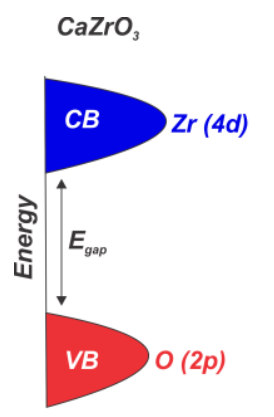

$\mathrm{Ca}_{1 \times x} \mathrm{Eu}_{\mathrm{x}} \mathrm{ZrO}_{3}$
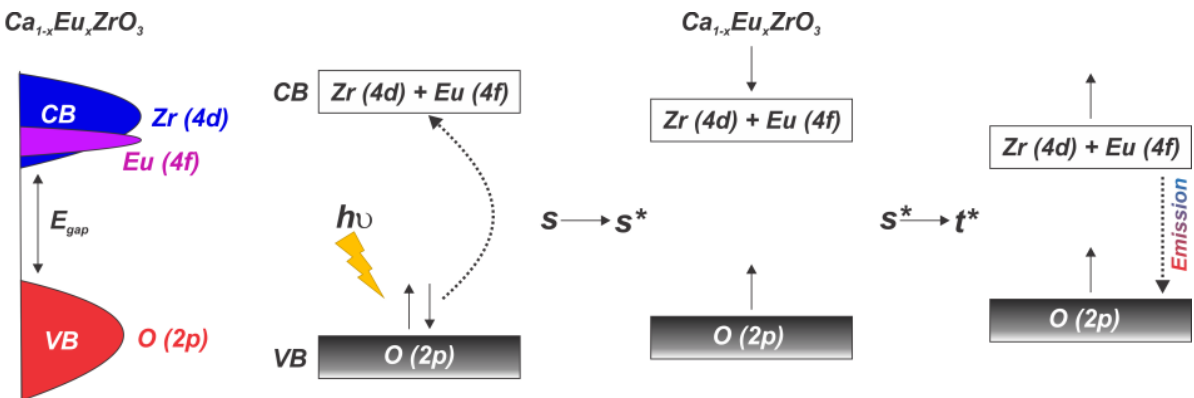

a)

b)

Fig. 7. Scheme to represent (a) the electronic structure for both pure and Eu-doped CZO material; (b) photo-induced electron transfer mechanism describing the singlet to triplet state excitation, as well as the electron decaiment related to the light emission. 
(a)

(b)

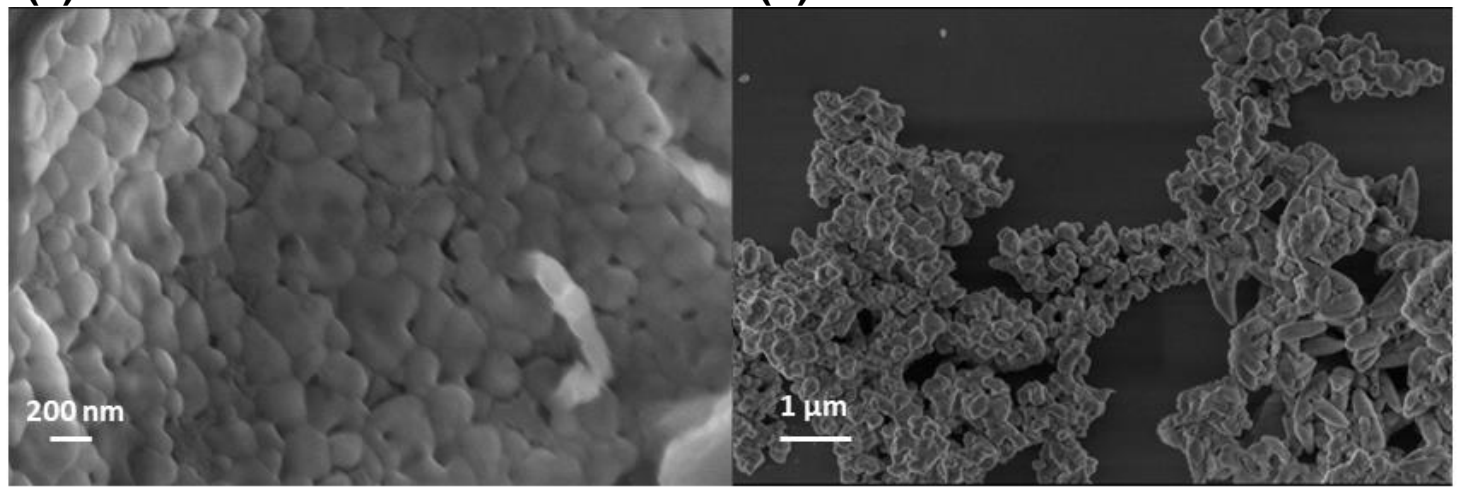

Fig. 8. FE-SEM micrographs. (a) pure CZO and (b) CZO:Eu ${ }^{3+}(10 \%)$. 
a)

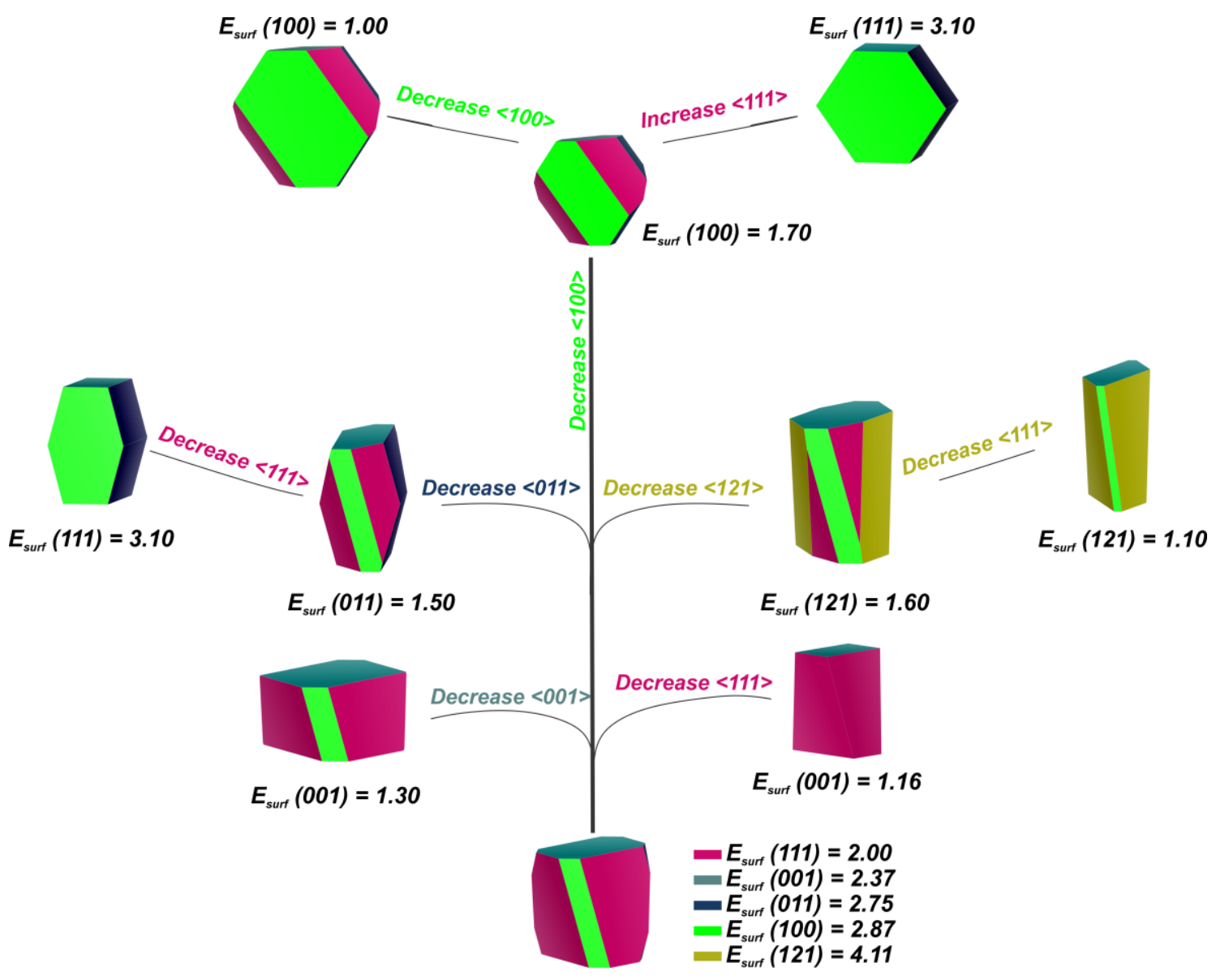


b)

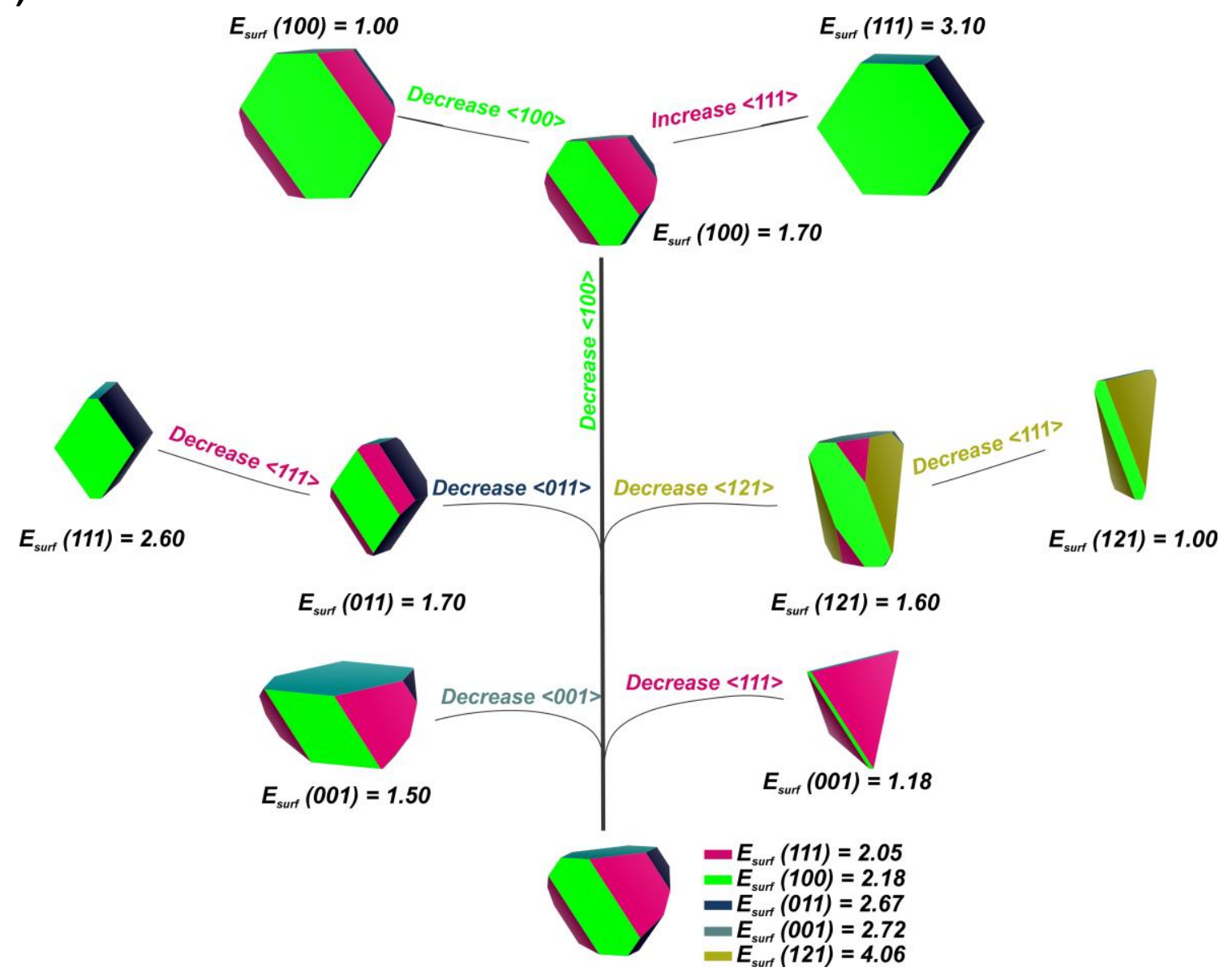

Fig. 9. Morphology modulations (a) $\mathrm{s}$ and (b) $t^{*}$ for $\mathrm{CZO}: \mathrm{Eu}^{3+}(12.5 \%)$ surfaces. 
Supporting Information

a)
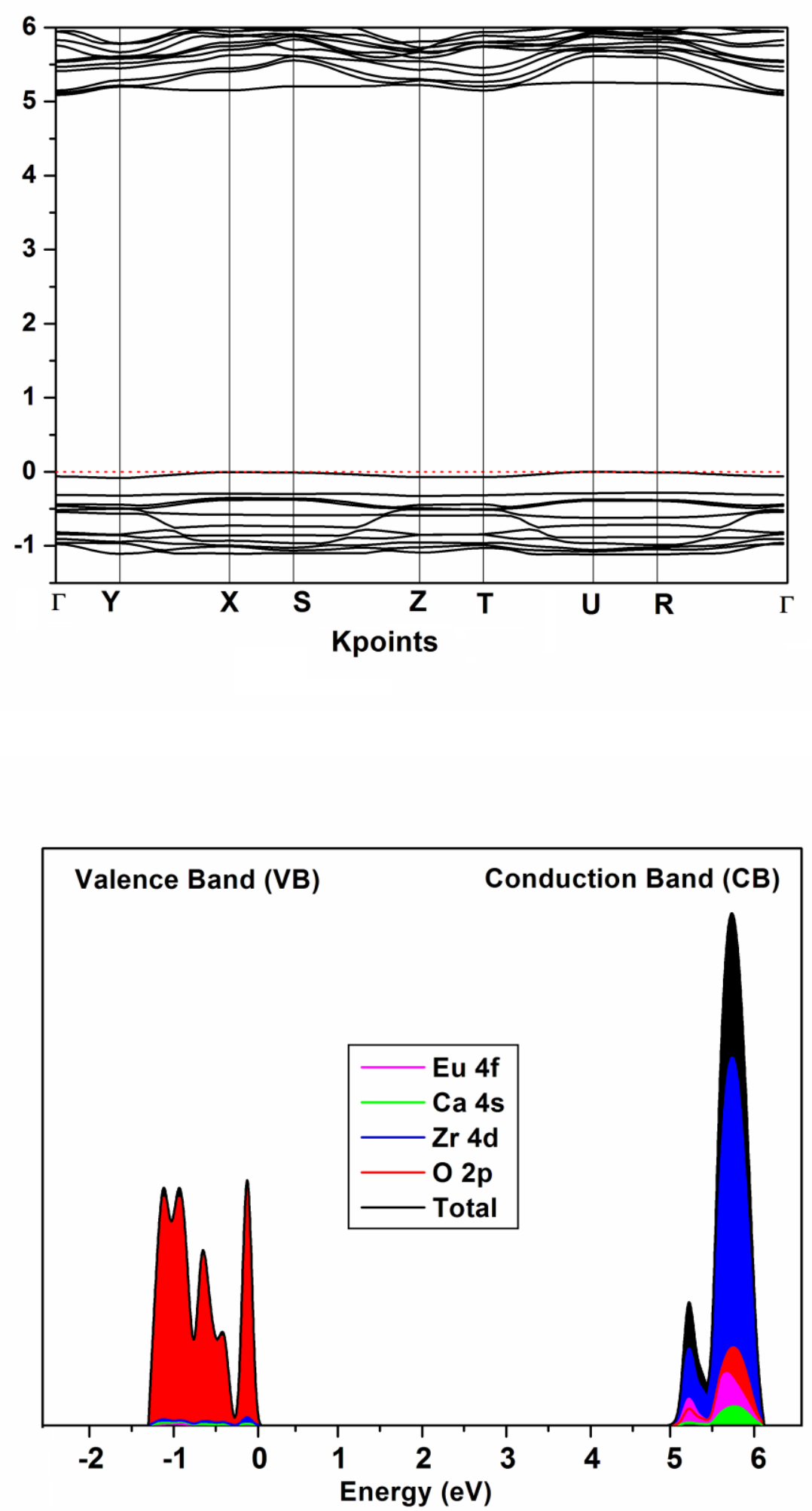
b)
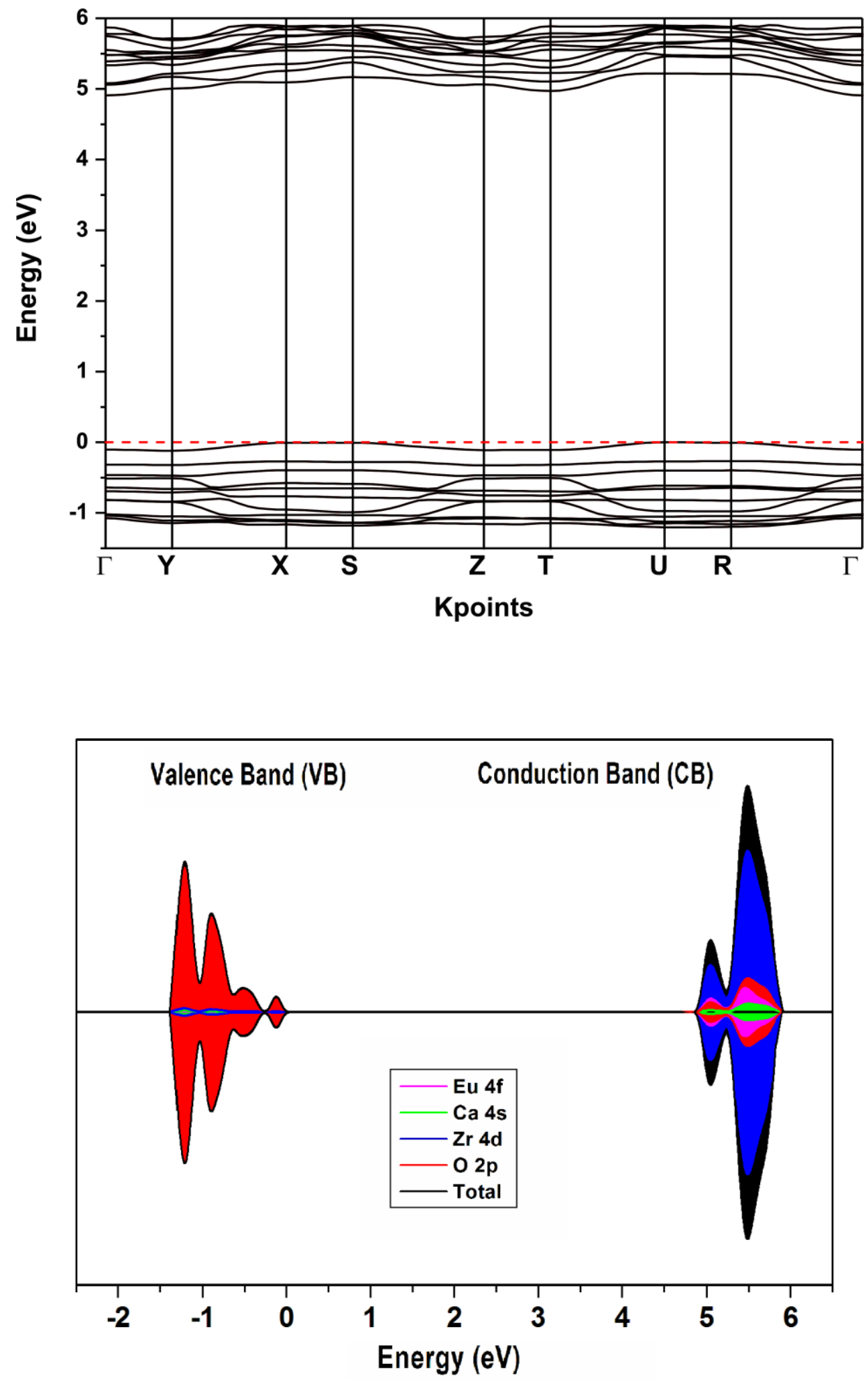

Figure S1. Band structure and DOS (a) s and (b) s* for CZO: $\mathrm{Eu}^{3+}(12.5 \%)$. 


\section{References}

1. S. K. Gupta, P. S. Ghosh, N. Pathak and R. Tewari, RSC Adv., 2015, 5, 5652656533.

2. J. Meyer and F. Tappe, Adv. Opt. Mater., 2015, 3, 424-430.

3. A. M. Ibarra-Ruiz, D. C. Rodríguez Burbano and J. A. Capobianco, Adv. Phys.: $X, 2016,1,194-225$.

4. S. P. Carlito, Jr., T. Yuxi, S. Villy and G. S. Ivan, Nanotechnology, 2016, 27, 082001.

5. S. A. Veldhuis, P. P. Boix, N. Yantara, M. Li, T. C. Sum, N. Mathews and S. G. Mhaisalkar, Adv. Mater., 2016, 28, 6804-6834.

6. N. A. Benedek and C. J. Fennie, J. Phys. Chem. C, 2013, 117, 13339-13349.

7. A. S. Bhalla, R. Guo and R. Roy, Mater. Res. Innov., 2000, 4, 3-26.

8. M. Johnsson and P. Lemmens, in Handbook of Magnetism and Advanced Magnetic Materials, John Wiley \& Sons, Ltd, 2007, DOI: 10.1002/9780470022184.hmm411.

9. A. Cammarata and J. M. Rondinelli, J. Chem. Phys., 2014, 141, 114704.

10. R. S. André, S. M. Zanetti, J. A. Varela and E. Longo, Ceram. Int., 2014, 40, 16627-16634.

11. X. Liu, J. Zhang, X. Ma, H. Sheng, P. Feng, L. Shi, R. Hu and Y. Wang, J. Alloy. Compd., 2013, 550, 451-458.

12. H. Zhang, X. Fu, S. Niu and Q. Xin, J. Lumin., 2008, 128, 1348-1352.

13. G. Róg, M. Dudek, A. Kozłowska-Róg and M. Bućko, Electrochim. Acta, 2002, 47, 4523-4529.

14. K. Kobayashi, S. Yamaguchi and Y. Iguchi, Solid State Ionics, 1998, 108, 355362.

15. M. S. Islam, R. A. Davies and J. D. Gale, Chem. Mater., 2001, 13, 2049-2055.

16. S. Sakaida, Y. Shimokawa, T. Asaka, S. Honda and Y. Iwamoto, Mater. Res. Bull., 2015, 67, 146-151.

17. J.-C. G. Bunzli and C. Piguet, Chem. Soc. Rev., 2005, 34, 1048-1077.

18. Y. Li and Y. Wang, J. Inf. Disp., 2011, 12, 93-96.

19. V. Singh, V. Kumar Rai and M. Haase, J. Appl. Phys., 2012, 112, 063105.

20. S. Katyayan and S. Agrawal, J. Mater. Sci.: Mater. El., 2018, 29, 2373-2383.

21. A. Maurya, R. S. Yadav, R. V. Yadav, S. B. Rai and A. Bahadur, RSC Adv., 2016, 6, 113469-113477.

22. Sheetal, V. B. Taxak, S. Singh, Mandeep and S. P. Khatkar, Optik - Int. J. Light El. Opt., 2014, 125, 6340-6343.

23. Y. Shimizu, S. Sakagami, K. Goto, Y. Nakachi and K. Ueda, Mater. Sci. Eng. B, 2009, 161, 100-103.

24. M.-H. Du, ECS J. Solid State Sc., 2016, 5, R3007-R3018.

25. M. C. Oliveira, L. Gracia, M. de Assis, I. L. V. Rosa, M. F. do Carmo Gurgel, E. Longo and J. Andrés, J. Alloy. Compd., 2017, 722, 981-995.

26. L. Gracia, J. Andrés, V. M. Longo, J. A. Varela and E. Longo, Chem. Phys. Lett., 2010, 493, 141-146.

27. M. L. Moreira, J. Andrés, L. Gracia, A. Beltrán, L. A. Montoro, J. A. Varela and E. Longo, J. Appl. Phys., 2013, 114, 043714.

28. M. L. Moreira, P. G. C. Buzolin, V. M. Longo, N. H. Nicoleti, J. R. Sambrano, M. S. Li, J. A. Varela and E. Longo, J. Phys. Chem. A, 2011, 115, 4482-4490. 
29. L. Gracia, V. M. Longo, L. S. Cavalcante, A. Beltrán, W. Avansi, M. S. Li, V. R. Mastelaro, J. A. Varela, E. Longo and J. Andrés, J. Appl. Phys., 2011, 110, 043501.

30. L. F. da Silva, J.-C. M'Peko, J. Andrés, A. Beltrán, L. Gracia, M. I. B. Bernardi, A. Mesquita, E. Antonelli, M. L. Moreira and V. R. Mastelaro, J. Phys. Chem. $C, 2014,118,4930-4940$.

31. V. M. Longo, M. das Graca Sampaio Costa, A. Zirpole Simoes, I. L. V. Rosa, C. O. P. Santos, J. Andres, E. Longo and J. A. Varela, Phys. Chem. Chem. Phys., 2010, 12, 7566-7579.

32. I. L. V. Rosa, M.C.Oliveira, M.Assis, M.Ferrer, R.S.André, E.Longo and M.F.C.Gurgel, Ceram. Int., 2015, 41, 3069-3074.

33. A. D. Becke, J. Chem. Phys, 1993, 98, 5648-5652.

34. C. T. Lee, W. T. Yang and R. G. Parr, Phys. Rev. B: Condens. Matter., 1988, 37, 785-789.

35. R. Dovesi, R. Orlando, A. Erba, C. M. Zicovich-Wilson, B. Civalleri, S. Casassa, L. Maschio, M. Ferrabone, M. De La Pierre, P. D'Arco, Y. Noël, M. Causà, M. Rérat and B. Kirtman, Int. J. Quantum Chem., 2014, 114, 1287-1317.

36. L. Valenzano, F. J. Torres, K. Doll, F. Pascale, C. M. Zicovich-Wilson and R. Dovesi, Z. Phys. Chem., 2006, 220, 893-912.

37. L. Valenzano, B. Civalleri, S. Chavan, S. Bordiga, M. H. Nilsen, S. Jakobsen, K. P. Lillerud and C. Lamberti, Chem. Mater., 2011, 23, 1700-1718.

38. F. Cora, Mol. Phys. , 2005, 103, 2483-2496

39. http://Www.Crystal.Unito.It/Basis_Sets.Html, Basis Set).

40. H. J. Monkhorst and J. D. Pack, Phys. rev. B, 1976, 13, 5188.

41. G. Wulff, zkri, 1901, 34, 449-530.

42. K. Momma and F. Izumi, J. Appl. Cryst., 2011, 44, 1272-1276.

43. I. Levin, T. G. Amos, S. M. Bell, L. Farber, T. A. Vanderah, R. S. Roth and B. H. Toby, J. Solid State Chem., 2003, 175, 170-181.

44. G. Blasse and A. Bril, Appl. Phys. Lett., 1967, 11, 53-55.

45. T. M. Mazzo, M. L. Moreira, I. M. Pinatti, F. C. Picon, E. R. Leite, I. L. V. Rosa, J. A. Varela, L. A. Perazolli and E. Longo, Opt. Mater., 2010, 32, 990997.

46. M. Romero, R. Faccio, J. Martínez, H. Pardo, B. Montenegro, C. C. Plá Cid, A. A. Pasa and Á. W. Mombrú, J. Solid State Chem., 2015, 221, 325-333.

47. L. F. Goncalves, L. S. R. Rocha, E. Longo and A. Z. Simões, J. Mater. Sci.: Mater. El., 2018, 29, 784-793.

48. A. C. Eduardo, A. T. de Figueiredo, M. Siu Li and E. Longo, Ceram. Int., 2014, 40, 15981-15984.

49. V. M. Longo, L. S. Cavalcante, M. G. S. Costa, M. L. Moreira, A. T. de Figueiredo, J. Andrés, J. A. Varela and E. Longo, Theor. Chem. Acc., 2009, 124, 385.

50. A. L. M. de Oliveira, M. R. S. Silva, H. Sales, E. Longo, A. S. Maia, A. G. Souza and I. M. G. Santos, J. Therm. Anal. Calorim., 2013, 114, 565-572.

51. A. A. G. Santiago, C. R. R. Almeida, R. L. Tranquilin, R. M. Nascimento, C. A. Paskocimas, E. Longo, F. V. Motta and M. R. D. Bomio, Ceram. Int., 2018, 44, 3775-3786.

52. L. X. Lovisa, M. C. Oliveira, J. Andrés, L. Gracia, M. S. Li, E. Longo, R. L. Tranquilin, C. A. Paskocimas, M. R. D. Bomio and F. V. Motta, J. Alloy. Compd., 2018, 750, 55-70. 
53. G. M. Gurgel, L. X. Lovisa, L. M. Pereira, F. V. Motta, M. S. Li, E. Longo, C. A. Paskocimas and M. R. D. Bomio, J. Alloy. Compd., 2017, 700, 130-137.

54. S. C. S. Lemos, F. C. Romeiro, L. F. de Paula, R. F. Gonçalves, A. P. de Moura, M. M. Ferrer, E. Longo, A. O. T. Patrocinio and R. C. Lima, J. Solid State Chem., 2017, 249, 58-63.

55. L. X. Lovisa, J. Andrés, L. Gracia, M. S. Li, C. A. Paskocimas, M. R. D. Bomio, V. D. Araujo, E. Longo and F. V. Motta, J. Alloy. Compd., 2017, 695, 30943103.

56. C. R. R. Almeida, L. X. Lovisa, A. A. G. Santiago, M. S. Li, E. Longo, C. A. Paskocimas, F. V. Motta and M. R. D. Bomio, J. Mater. Sci.: Mater. El., 2017, 28, 16867-16879.

57. J. Huang, L. Zhou, Y. Lan, F. Gong, Q. L and J. Sun, Cent. Eur. J. Phys., 2011, 9, 975-979.

58. V. R. L. Constantino, M. A. Bizeto and H. F. Brito, J. Alloy. Compd., 1998, 278, 142-148.

59. T. D. Dunbar, W. L. Warren, B. A. Tuttle, C. A. Randall and Y. Tsur, J. Phys. Chem. B, 2004, 108, 908-917.

60. G. Blasse, Luminescence of Inorganic Solid, Plenum Press, New York and London, 1967.

61. T. Yoed, H. Atsushi, S. Ian and A. R. Clive, Jpn J. Appl. Phys., 2001, 40, 255.

62. G. Wulff, Kristallogr. Miner, 1901, 34, 449-530.

63. A. F. Gouveia, M. M. Ferrer, J. R. Sambrano, J. Andrés and E. Longo, Chem. Phys. Lett., 2016, 660, 87-92.

64. M. M. Ferrer, A. F. Gouveia, L. Gracia, E. Longo and J. Andrés, Modelling Simul. Mater. Sci. Eng., 2016, 24, 025007.

65. M. T. Fabbro, C. Saliby, L. R. Rios, F. A. L. Porta, L. E. Gracia, M. S. Li, J. Andrés, L. P. S. Santos and E. Longo, Sci. Technol. Adv. Mater, 2015, 16, 065002.

66. R.A.P. Ribeiro, S.R. de Lazaro, L. Gracia, E. Longo and J. Andrés, J. Magn. Magn. Mater., 2017, DOI: doi.org/10.1016/j.jmmm.2017.11.025. 